\title{
Cornual Pregnancy
}

F WAZED, ${ }^{1}$ N SULTANA, ${ }^{2}$ S AHAMED, ${ }^{3} \mathrm{JH} \mathrm{KHAN}^{4}{ }^{4} \mathrm{~S} \mathrm{ROUF}^{5}{ }^{5} \mathrm{UMOJUMDER}^{6}$

\begin{abstract}
:
Cornual pregnancy is rare form of ectopic pregnancy where implantation occurs in the cavity of a rudimentary horn of the uterus. It is the diagnostic and therapeutic challenge with potential sever consequence if uterine rupture occurs with massive intra abdominal haemorrhage. We report a case of misdiagnosed rupture cornual pregnancy occurring at 12 weeks gestation. First USG revealed intra uterine pregnancy. Repeat USG showed abdominal pregnancy sac but cornual pregnancy was not diagnosed and uterine anomaly was not detected. The correct diagnosis was made at emergency laparotomy. An intact pregnancy sac of 12 weeks fetus was seen in abdominal cavity. Placenta and pregnancy sac was adherent to omentum and torn end of left cornu of the bicornuate uterus. Left sided cornu was resceted keeping both the ovaries and tubes intact.
\end{abstract}

Keyword: Cornual pregnancy, Ectopic pregnancy, Uterine malformation.

\section{Introduction :}

Cornual pregnancy is very rare ( 1 in 100,000 maternities) condition occurs in the atretic horn of bicornuate uterus and has a maternal mortality of $5 \% .{ }^{1}$ In this from of ectopic pregnancy implantation occurs in the cavity of rudimentary horn of uterus. The horn does not always communicates with rest of the uterine cavity in which case it must be assumed that spermatozoa ascend through the other horn and tube and fertilize an ovum in the peritoneal cavity. This then enters the tube of the rudimentary horn. ${ }^{2}$ It also refers to a pregnancy in interstitial segment of a unicornuate or bicornuate uterus. The term cornual pregnancy is used interchangeably in the United States as a synonym for interstitial pregnancy. ${ }^{3}$ Cornual pregnancy accounts for 1$2 \%$ ectopic pregnancies and $20 \%$ of cases that advance beyond 12 wks of gestation and finally rupture. ${ }^{4-5}$ Uterine rupture may result in massive bleeding due to richness of the local vascularilization through the branches of the uterine and ovarian arteries leading to higher mortality rate ${ }^{5}$. We report a case of a misdiagnosed ruptured cornual pregnancy occurring at 12 wks of gestation.

\section{Case Report}

A 23 years of old primiparous lady presented to the Obstetric and Gynaecology department of Dhaka Medical College

1. Assoc. Prof. Obs and Gynae, DMCH

2. Assoc. Prof. Obs and Gynae. NMCH

3. Medical Officer Obs and Gynae, DMCH

4. Assit. Prof. Obs and Gynae, DMCH

5. Professor, Obs and Gynae, DMCH

6. Assistant Prof. Obs and Gynae, DMCH

Correspondence : Dr. Feroza Wazed - Associate Professor, Department of Obs. and Gynae, DMCH
Hospital with the complaints of amenorrhea for 3 months and lower abdominal pain for last 10 days. She developed amenorrhea for 12 weak with early sign symptoms of pregnancy. She attained menarche at the age of 14 years. She had regular cycle of 28 day cycle without any dysnenorrhoea and menorrhagia. Her LMP was to 28/03/12 and accordingly she had 12 weeks pregnancy. She was married for 1 year. This pregnancy was concieved spontaneously. She was not a booked case. 10 days priror to her admission in DMCH she developed severe lower abdominal pain and syncopal attack. For this reason she was brought to a local hospital.There she was treated conservatively. USG was done. Sonographic finding revealed a gravid uterus containing single fetus. Tiny fetal pole was seen. CRL of fetus was about $5.4 \mathrm{~cm}$ which corrsponds to about 12 weeks of gestation. Cardiac pulsation was present. She was discharged as a case of 12 weeks intra uterine viable pregnancy. After 3-5 days the patient again developed severe agonizing pain in lower abdomen without pervaginal bleeding and got admission to the same hospital. Again USG of abdomen was done. Sonographic finding revealed empty uterus and in the abdominal cavity there is a intact pregnancy sac with 12 weeks size fetus within it. Fetal movement or cardiac pulsation was absent. Cul -de- sac was free from collection. So she was referred to $\mathrm{DMCH}$ for further management. On examination, she was malnourished ill looking, moderately anaemic, afebrile. Her lung fields were clear clinically. Her pulse was 110 beats per min, BP was 90/ $60 \mathrm{mmHg}$. Abdomen - was soft but tenderness was present in lower abdomen. An ill defined mass was felt in left lower abdomen. Per vaginal examination revealed a bulky uterus. Fornices were full with no per vaginal bleeding. She had cervical motion tenderness. 3 units of fresh whole blood 
was transfused. On suspicion of ongoing abdominal bleeding an emergency laparotony was done under spinal anaesthesia. After opening the peritoneun a large blood clot came out. After removal of blood clot, a pregnancy sac of 12 week size fetus was found. Fetus was dead and sac was intact. Placenta and pregnancy sac was adherent to omentum and torn end of left cornual of bi cornuate uterus. Left sided cornu found ruptured on the fundus. Bleeding was moderate. There was no connection between left horn and cervical canal. Right and Left bellopian tube and overies are normal. Left sided cornu was resected keeping both the ovaries and tubes intact. After proper haemostasis and peritoneal toileting abdomen was closed in layers. A drain was put in situ. The patient had an eventful recovery. There was discharge from the wound from $3^{\text {rd }}$ POD. There was wound gap. Secondary suture was given. Antibiotic was given

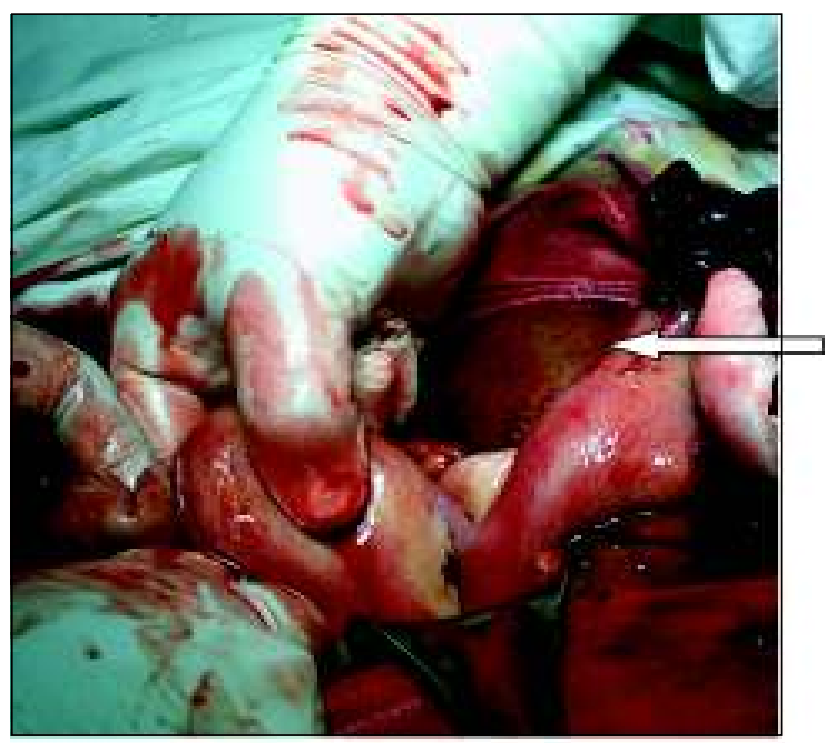

Bicornuate uterus with rupture left horn

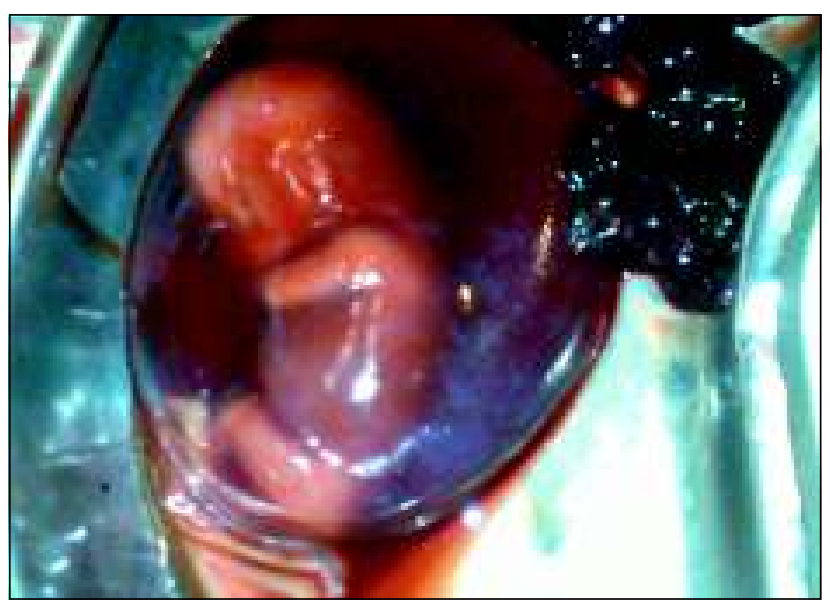

12 Weeks pregnancy sac. according to $\mathrm{C} / \mathrm{S}$ of discharge from wound. The patient was discharge after 9 days with healthy scar and haematinics. She was reassured and encouraged to continue haematinic and contraception.

\section{Discussion:}

The prevalence of congenital uterine malformation is about $6,7 \%$ in the female population and higher in women with reproductive problems. ${ }^{6} \mathrm{Bi}$ cornuate uterus is an abnormality with a partial non fusion of the mullerian duct resulting in a central myometrium that can extend as far down as the internal cervical opening. This malformation makes up approximately $3 \%$ of the uterene malformation. ${ }^{6}$ The malformation in itself is asymptomatic but is associated with an increased rate of reproductive problems including repeated late abortion or miscarriage. ${ }^{7,8}$ The anomaly is often overlooked in routing gynecological examination. Sonohysterograpical has been suggested as a screening tool to identify congenital malformation in infertile patient. As 2D USG,diagnostic hysteroscopy, hysterosalpingography all have a low sensitivity. ${ }^{6,9}$ Cornual pregnancy is implanted in the upper lateral portion of a bicornuate or septate uterus. ${ }^{10}$ The symptoms are similar to those of tubal gestation except that dramatic symptoms occur late. Asymmetrical enlargement of uterus, real or apparent, is a feature of normal early pregnancy. Though the presentation of our case was like that. The patient was admitted to kaligonj hospital of pregnancy with pain in abdomen and was treated conservatively and diagnosed as a case of 12 wks intra uterine pregnancy. The general and local reaction are the same as for tubal pregnancy. An important feature of cornual pregnancy is that the sac is surrounded by myometrium and even though this is poorly developed, it can contain pregnancy for a longer time than can the tube or ovary rupture of the horn .Therefore does not usually take place until the 12-20wks but when it does severe bleeding many occur. Our patient was moderately pale with BP 90/60 mmHg. There was also intra peritoneal bleeding due to rupture of rudimentary horn of bicornuate uterus. Repeated USG showed uterus was empty. About 12 wks size pregnancy sac is found in abdominal cavity without fetal movement and cardiac activity. Her first USG was actually misleading as the pregnancy was interpreted as a normal intra uterine pregnancy. No bicornuate uterus was detected. So an advanced rupture cornual pregnancy in the case was medical emergency. Patient was treated with laparotomy. In this case we took decision of laparotomy because the pregnancy sac was in peritoneal cavity with moderated amount of intra peritoneal haemorrhage. 


\section{Conclusion:}

Laparotomy is essential in the haemodynamically unstable patient with abdominal pregnancy sac due to rupture horn of bicornuate uterus. The affected horn together with the pregnancy being usually removed. This case was clearly brought to fore the need to have a high index of suspicion for ectopic pregnancy whenever a woman of reproductive age group present with a history of amenorrhea and lower abdominal pain with or without vaginal bleeding even if she is haemodynamically stable.

\section{Conflict of Interest : None}

\section{References:}

1. Dewhursts test book of obstetric gynalecology for post graduates-Edited by D-keth Edmonds. Miscarriage, ectopic and trophoblastic disease,P-71

2. Jeff coate's principles of gynalecology, Seventh international edition revised by Protap Kumar MD,FICOG and Narendra Malhotra MD,FICOG, Ectopic Pregnancy P156.

3. Tulaudi T, Al- jaroudi D, Interstitian pregnancy: Result generated from The society of reproductive, surgeons registry .Obstet gynaecol 2004,103:47-50.
4. U Ince, Ma osnanagaoglu and H boskoaya. A rapture cornual ectopic pregnancy at $18 \mathrm{wks}$ gestation: A case report. The internat journal of gynalecology and obstetrics; 2008:9 (2).

5. Jayantic C, Asma A, Fatai As,Laure I.Davicl G-Arere Seguel following corneal ectopic pregnancy: A care report .BMJ care reports 2009;10.1614

6. S.H. Saravelos. K.A. cock and T.C.Li,'

7. F. Raga, C Bauset, J. Remohi, F. Bonilla-musoles, C. Simon, and A pellicer, Reproductive impact of Congenital mullerian anomalies,Human Reproduction Vol:12, No.10 pp.2277-2281 1997.

8. B.W. Rackow and A. Arici, 'Reproductive performance of women with mullerian, anomalies,'current opinion in obstetrics and gynecology vol.19,no.3,pp.229-237, 2007.

9. A. Ludwin, I. Ludwin,T.Banas,Aknafel,M mindzy - block i and A.Basta . "Diagnostic accuracy of SonohysterographyHysterosalpingography and diagnostic hystroscopy in diagnosis of arcuat, septate and bicornuate uterus".Journal obstctric and gynaecology research ,Vol.37, no.3.pp.178186,2011 .

10. A. Malinowski and S.K.balis'Semantics and petfalss in the diagnosie of cornual / interstitial pregnancy' Fertility and sterility. Vol, 86, No.6, pp 1764-e11-1764-e14,2006. 